\title{
Fatal tension pneumoperitoneum due to aerophagy
}

\author{
G. H. HutChINSON \\ M.B., Ch.B., F.R.C.S. Eng., F.R.C.S.Ed.
}

\author{
D. M. Alderson \\ M.B. B.S.
}

\author{
L. A. Turnberg \\ M.D., F.R.C.P.
}

North Manchester General Hospital (Teaching) and University Department of Medicine, Hope Hospital

(University of Manchester School of Medicine), Salford M6 8HD

\begin{abstract}
Summary
A case of fatal tension pneumoperitoneum following gastric perforation due to aerophagy is described. Comment is made on the probable pathogenesis.
\end{abstract}

\section{Introduction}

A tension pneumoperitoneum occurs when free gas progressively collects under tension in the peritoneal cavity. It is an occasional complication of acute ulcerative colitis (Brooke, 1959) and has been described following large bowel anastomosis (Hughes, Cuthbertson and Buntine, 1964). In the neonate, spontaneous pneumoperitoneum has occurred singly (Aranda, Stern and Dunbar, 1972) and in association with a pneumothorax (Edward, Symchych and Redo, 1977).

A patient is described who developed a fatal tension pneumoperitoneum following ischaemic perforation of a grossly dilated stomach caused by aerophagy.

\section{Case report}

A 28-year-old female secretary first presented to the gastroenterology clinic at Hope Hospital, Salford, in 1973, complaining of occasional watery diarrhoea, excessive flatus and intermittent abdominal distension. There was no rectal bleeding and she offered that she swallowed air frequently. She had always been an air swallower and this had been an increasing problem since her marriage at the age of 24 years. She was very anxious to conceive and had attended a subfertility clinic from the age of 26 years. Examination confirmed gaseous distension of the abdomen. Sigmoidoscopy revealed a normal looking mucosa and a subsequent barium enema was normal except for colonic gaseous distension. There was no narrow segment suggestive of Hirschprung's disease. Chlordiazepoxide and mebeverine were prescribed and she gained symptomatic relief.

During the next year, whilst on holiday in London, she was admitted to hospital with signs and symp- toms of subacute large bowel obstruction. She was $\frac{3}{3}$. treated successfully with intravenous fluids and nasogastric aspiration. A barium meal and follow-os through examination revealed what seemed to be an. enormous megacolon but colonoscopy showed a ir normal mucosal appearance and rectal biopsies $\sigma$ confirmed the presence of ganglion cells.

She admitted to being very anxious and agreed to see a psychiatrist. He was impressed by the bland $\subseteq$ way in which she related her symptoms and thought her manner one of 'belle indifférence' seen classicalty $\vec{\bullet}$ in hysterical conditions. Again she pinned her. anxieties on her inability to conceive.

She was now 31 years old and continued to attert a subfertility clinic. An attempt to regulate her menstrual cycle was made by inducing ovulation

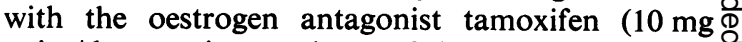
twice/day starting on day 2 of the cycle, for 4 days) $\stackrel{\varrho}{\overrightarrow{7}}$ and within 5 months she was pregnant.

Her antenatal progress was uneventful until the 34th week when she became impacted with faeces, with spurious diarrhoea. Treatment with phosphate enemata and oral magnesium sulphate was successful $\frac{3}{3}$ and 2 weeks later she went into spontaneous labour and delivered a live male infant. Her post-natal $\underline{3}$. history was unremarkable. Her air swallowing, $\delta$ abdominal distension and bowel symptoms all regressed for several months.

She was keen to embark upon another pregnancy immediately and 6 months post-delivery was started on a further course of tamoxifen. There was no evidence of abdominal distension and $\mathrm{N}$ mentally she was more settled. After 3 months a $N$ prolactin level was found to be slightly elevated $\underset{\mathrm{N}}{\mathrm{N}}$ and bromocriptine $5 \mathrm{mg}$ thrice/day was substituted. 0 This shortened her cycle excessively and the dose was reduced to $2 \cdot 4 \mathrm{mg}$ twice/day. After 4 months, tamoxifen was again added and this regimen was $\stackrel{\oplus}{\rightarrow}$ continued in the 5 months before her final admission.

At the age of 33 years she was referred for urgent admission to North Manchester General Hospital, 
with an episode of gross abdominal distension. On this occasion her general practitioner had discovered a liver edge palpable below the umbilicus and an easily palpable spleen. During the week before her admission she had suffered 'a lot of worries' and her abdomen became gradually distended. She had noticed some mild, colicky, central abdominal pain which had become worse $12 \mathrm{hr}$ before admission but which had never been severe.

On admission she was shocked; BP 90/50 $\mathrm{mmHg}$. Her respiration was laboured. The abdomen was markedly distended and the palpable liver and spleen was confirmed. The patient passed a normal stool, yet the abdomen continued rapidly to distend. It was hyper-resonant to percussion and silent on auscultation. Rectal examination revealed a voluminous rectum containing soft faeces. Palpating the rectal mucosa gave the digital sensation of crepitus, as in surgical emphysema.

Resuscitation commenced with intravenous plasma and oxygen by mask and plain X-rays were obtained (Figs 1 and 2). The films revealed grossly distended bowel with thickened walls and appearances of pneumatosis coli. There was a large volume of free gas splinting an elevated diaphragm with the liver displaced downwards and medially.

Within minutes the patient's pulse became irregular and blood pressure unrecordable. She lost consciousness in asystole. An endotracheal tube was passed but efforts to ventilate the patient and

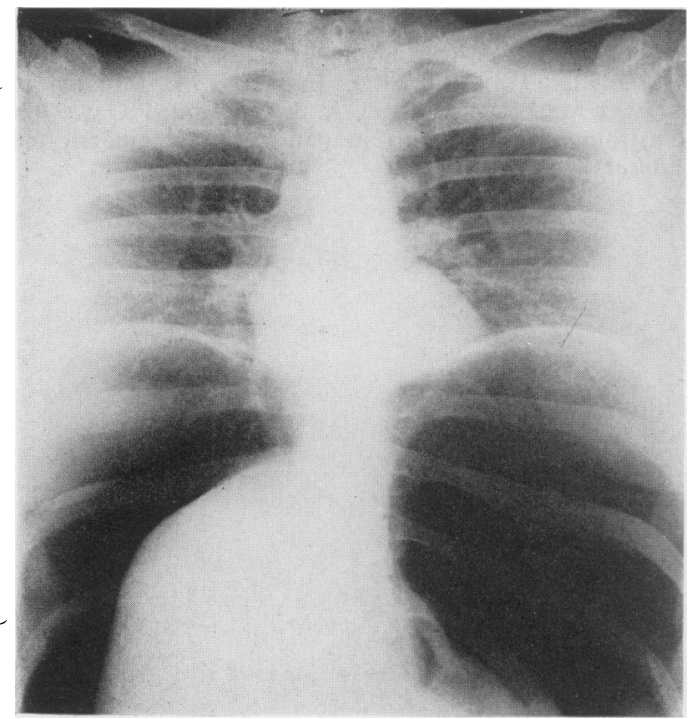

Fig. 1. Erect film of chest and upper abdomen demonstrating a massive pneumoperitoneum with classical 'saddlebag' picture of liver surrounded by air which has accumulated under the diaphragm.

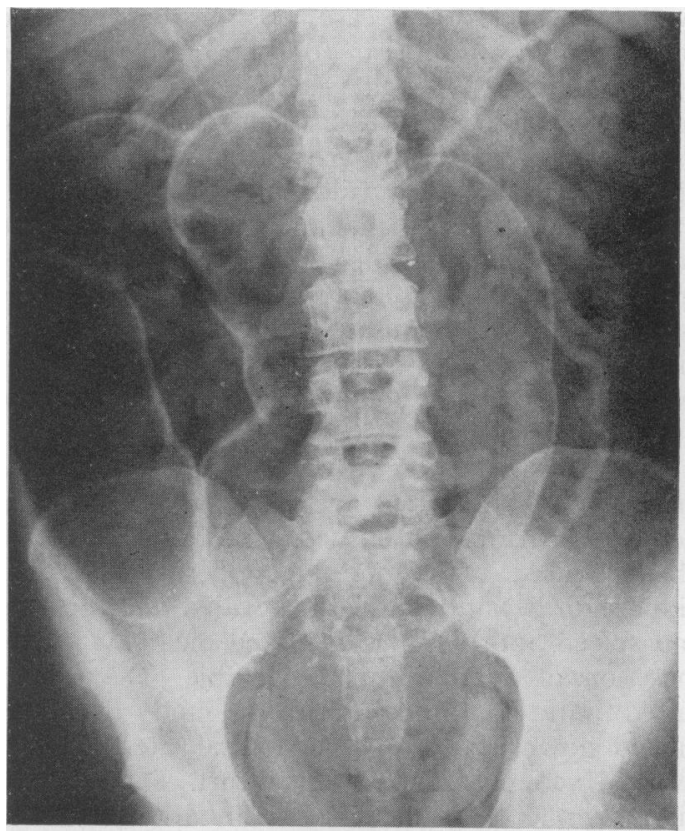

Fig. 2. Supine abdominal film showing gross dilatation of the large bowel which has thickened walls and pneumotosis cystoides, most clearly seen as a dark line of gas beneath the rectal mucosa.

perform external cardiac massage were impaired by the now drum-tight abdomen. Thoracotomy via the 5 th left interspace was performed to allow internal cardiac massage, and the diaphragm was punctured to allow peritoneal deflation. A jet of odourless gas escaped with considerable force, ventilation became more effective and spontaneous ventricular contractions soon returned, maintaining a strong femoral pulse.

The patient was transferred to the intensive-care unit where the thoracotomy was closed with underwater seal drainage, but her pupils had already become dilated and unresponsive. After a short period of Cheyne-Stokes respiration she died.

At post-mortem the colon was distended and showed pneumotosis coli throughout its length, but there was no perforation. However, the whole stomach was a dusky blue colour with the consistency of wet blotting paper and was obviously ischaemic, with a 2-cm diameter anterior perforation in a frankly gangrenous portion. Histological examination confirmed ischaemic necrosis of the stomach. The large bowel had air-cysts and a normal complement of ganglion cells throughout its length.

\section{Discussion}

Hackl (1973) reported a case of pathological aerophagy causing death in a mentally ill patient 
aged 46 years. In that case, post-mortem revealed an enormous meteorism of the gastrointestinal tract, but no viscus had perforated and there had been no tension pneumoperitoneum. Death seemed to have been caused by gross displacement of the diaphragm leading to cardiac failure.

It must be assumed that the present patient had been a chronic air-swallower for many years. Her episodes of colonic gaseous distension were probably caused by this mechanism but an underlying motor disturbance cannot be entirely excluded. However, gross distortion of colonic innervation was not found on histological inspection.

On this last occasion the degree of gastric ballooning had so attenuated the vascular supply that ischaemic perforation ensued, and continued aerophagy caused a tension pneumoperitoneum. The diaphragm became markedly elevated and the liver and spleen both became displaced medially-hence these organs were initially palpable. The greatly raised intra-abdominal pressure and the liver hinged downwards from its normal site, led to a reduced venous return to the heart. The elevated diaphragm led to further cardiac embarrassment and eventually asystole. Deflation at thoracotomy successfully restored a cardiac return but irreparable cerebral hypoxia had occurred.

The authors do not believe that the bromocriptine medication played a contributory role in pathogenesis. Vasospastic reactions have been recorded in acromegalic patients, receiving large doses of bromocriptine long term, but most commonly these patients have been suffering from Raynaud's phenomenon (Wass, Thorner and Besser, 1976a). Isolated examples of peptic ulceration have been reported in patients on bromocriptine but invariably they have been acromegalics on a high dose, and there is no evidence to suggest that bromocriptine $\cong$ increases the incidence of peptic ulceration (Wass $\Sigma$ et al., 1976b).

In the case described, events certainly progressed $c$. in rapid and dramatic fashion. But it is clear, too, $\vec{F}$ that if laparotomy had proved possible, a total $\stackrel{\rho}{?}$ gastrectomy would have been required in the presence of global distension of the large bowel. It is also interesting to speculate that in this case $\frac{\text { ? }}{\overrightarrow{0}}$ pneumotosis coli not detected in early radiographs $\mathbb{Q}$ had probably resulted from swallowed air being $๗$ forced through and beneath the colonic mucosa $\vec{O}$ over an unknown period of time.

\section{Acknowledgments}

We would like to thank Professor V. Tindall who supplied the information from the sub-fertility clinic, Dr D. De- $\exists$ Kretzer, Consultant Histopathologist, and Miss Perry of the Department of Medical Illustration at North Manchester General Hospital.

\section{References}

Aranda, J.V., Stern, L. \& Dunbar, J.S. (1972) Pneumothorax with pneumoperitoneum in a newborn infant. American Journal of Diseases of Children, 123, 163.

BROOKE, B.M. (1959) Granulomatous diseases of the intestine. Lancet, ii, 745.

EdWARD, B.I., Symchych, P.S. \& Redo, S.F. (1977) Pneumoperitoneum without ruptured viscus in the neonate: a cass report and review of the literature. Journal of Pediatre Surgery, 12, 537.

HACKL, H. (1973) Pathologische Aerophagie als Todesurache Medizinische Klinik, 68, 667.

Hughes, E.S.R., Cuthbertson, A.M. \& Buntine, J.A. (1964) Postoperative tension pneumoperitoneum. British Journal of Surgery, 51, 274.

WASS, J.A.H., ThORNER, M.O. \& Besser, G.M. (1976a) Digital vasospasm with bromocriptine. Lancet, $\mathbf{i}, 1135$.

Wass, J.A.H., ThORner, M.O., BesSer, G.M., Morris, D., 응 Stuart Mason, A., Liuzzi, A. \& Chiodini, P.G. (1976b) Gastrointestinal bleeding in patients on bromocriptine. Lancet, ii, 851. 